\title{
ERS International Congress, Madrid, 2019: highlights from the Paediatric Assembly
}

\author{
Raffaella Nenna (1) ${ }^{1}$, Monique Slaats ${ }^{2}$, Refika Ersu ${ }^{3}$, David Lo ${ }^{4,5}$, Sejal Seglani ${ }^{6}$, \\ Claire Nissenbaum ${ }^{7,8}$, Alex R. Horsley (10,8, Marijke Proesmans ${ }^{9}$, \\ Laura Petrarca ${ }^{1}$, Emma Williams ${ }^{10}$, Theodore Dassios ${ }^{10}$, Cristina Ardura- \\ Garcia $^{11}$, Liesbeth Duijts (1) ${ }^{12}$, Honorata Marczak ${ }^{13}$, Deborah Snijders ${ }^{14}$, \\ Robbert Rottier $^{15,16}$, Cho-Ming Chao ${ }^{17,18}$, Marielle W. Pijnenburg ${ }^{12}$ and \\ Jonathan Grigg ${ }^{19}$
}

Affiliations: 'Maternal-Infantile and Urological Science Dept, “Sapienza” University of Rome, Rome, Italy. ${ }^{2}$ Dept of Paediatric Medicine, Antwerp University Hospital, Edegem, Belgium. ${ }^{3}$ Dept of Paediatric Pulmonology, Children's Hospital of Eastern Ontario, Ottawa, Canada. "Dept of Paediatric Respiratory Medicine, University Hospitals of Leicester, Leicester, UK. ${ }^{5}$ Dept of Respiratory Sciences, University of Leicester, Leicester, UK. 'Inflammation, Repair and Development Section, National Heart and Lung Institute, Faculty of Medicine, Imperial College, London, UK. ${ }^{7}$ University of Manchester, Manchester, UK. ${ }^{8}$ Manchester University Foundation NHS Trust, Manchester, UK. ${ }^{9}$ Dept of Pediatrics, University Hospitals Leuven, Leuven, Belgium. ${ }^{10}$ Women and Children's Health, School of Life Course Sciences, Faculty of Life Sciences and Medicine, King's College London, London, UK. ${ }^{11}$ Institute of Social and Preventive Medicine, University of Bern, Bern, Switzerland. ${ }^{12}$ Erasmus MC-Sophia, University Medical Centre Rotterdam, Dept of Paediatrics, Division of Paediatric Pulmonology and Allergology, Rotterdam, The Netherlands. ${ }^{13}$ Dept of Paediatric Pneumonology and Allergy, Medical University of Warsaw, Warszaw, Poland. ${ }^{14}$ Dipartimento Salute della Donna e del Bambino, Università degli Studi di Padova, Padua, Italy. ${ }^{15}$ Dept of Pediatric Surgery, Erasmus Medical Center-Sophia Children's Hospital, Rotterdam, The Netherlands. ${ }^{16}$ Dept of Cell Biology, Erasmus Medical Center, Rotterdam, The Netherlands. ${ }^{17}$ Cardio-Pulmonary Institute, German Center for Lung Research, Department of Internal Medicine II, Universities of Gießen and Marburg Lung Center, Gießen, Germany. ${ }^{18}$ University Children's Hospital Gießen, Dept of General Pediatrics and Neonatology, Justus-LiebigUniversity, Gießen, Germany. ${ }^{19}$ Centre for Paediatrics, Queen Mary University London, London, UK.

Correspondence: Raffaella Nenna, Dept of Paediatrics, “Sapienza” University of Rome, V. le Regina Elena 324, 00161, Rome, Italy. E-mail: raffaella.nennaQuniroma1.it

ABSTRACT In this article, the Group Chairs and the Early Career Members of the Paediatric Assembly of the European Respiratory Society (ERS) highlight some of the most interesting findings in the field of paediatrics presented at the 2019 ERS International Congress, which was held in Madrid, Spain. The main findings from each group are summarised at the end of each chapter.

@ERSpublications

Key paediatric messages from the 2019 \#ERSCongress https://bit.ly/2XA8UJB

Cite this article as: Nenna R, Slaats M, Ersu R, et al. ERS International Congress, Madrid, 2019: highlights from the Paediatric Assembly. ERJ Open Res 2020; 6: 00063-2020 [https://doi.org/10.1183/ 23120541.00063-2020].

Received: 10 Feb 2020 | Accepted after revision: 31 May 2020

Copyright $\odot$ ERS 2020. This article is open access and distributed under the terms of the Creative Commons Attribution Non-Commercial Licence 4.0. 


\section{Introduction}

The Paediatric Assembly (Assembly 7) now has over 1500 members. At the European Respiratory Society International Congress in Madrid, Spain, we came together to review the latest paediatric respiratory research, including new data from over 350 abstracts of which half were submitted and presented by Early Career Members. With significant input from our Early Career Members, herein we will review some of the paediatric highlights from the Congress. We selected the most quoted abstract from each paediatric group.

\section{Paediatric respiratory physiology and sleep}

There is a suggestion that repetitive episodes of hypoxia may affect changes in bone metabolism [1, 2]. SIES et al. [3] investigated the association of obstructive sleep apnoea (OSA) and risk of early osteoporosis in 150 children aged 1017 years. The screening tool was measuring the of speed of sound (SOS) by quantitative ultrasound of calcaneus-achilles. It has long been known that measurement of SOS along the length of a bone gives information about the bone density, the micro-architecture, cortical thickness and elasticity [4]. A slower SOS means a more fragile bone. In this study, patients with OSA had a slower SOS by quantitative ultrasound of calcaneus-achilles compared to controls suggesting risk for early osteoporosis. Limitation of this study was that the majority of children in the OSA group were obese which could also be a risk factor for lower vitamin $\mathrm{D}$ levels and hence osteoporosis.

An observational descriptive study was conducted by GHARIBZADEH Hizal et al. [5] to assess the sleep-related respiratory disorders in 42 children with Down syndrome at Hacettepe University (Ankara, Turkey). OSA by polysomnography (PSG) was present in $97.6 \%$ of children in which $28.5 \%$ of them had severe OSA. Most notable was that the majority of the families did not describe any clinical signs of sleep disturbance.

Two abstracts presented data about alternative methods for diagnosis of OSA in children. The American Academy of Sleep Medicine (AASM) recommends the use of oronasal thermistor and nasal cannula to detect respiratory events and respiratory inductance plethysmography to characterise apnoeas [6]. However, nasal cannulas have a poor scorability. AMADDEO et al. [7] evaluated the use of tracheal sounds suprasternal pressure (SSP) as an additional sensor for the detection and characterisation of respiratory events during sleep in 17 children. They compared three methods: standard AASM signals (scoring 1); combination of tracheal sounds and SSP with respiratory inductance plethysmography flow and oxygen saturation measured by pulse oximetry without oronasal thermistor and nasal cannula (scoring 2); and tracheal sounds and SSP combined with oxygen saturation measured by pulse oximetry 2 only (scoring 3 ). The tracheal sounds, SSP and respiratory inductance plethysmography flow signals were present during $95 \%, 96 \%$ and $99 \%$ of the validated recording time, respectively, with $79 \%$ and $85 \%$ for nasal cannulas and thermistor. Sensitivity for apnoea and hypopnoea detection was $97 \%$ and $77 \%$ (scoring 2) and $95 \%$ and $76 \%$ (scoring 3), respectively. Investigators concluded that scoring with tracheal sounds and SSP can be used for the detection and characterisation of apnoeas in children, and may be used as an alternative.

Delta 12s, a measure of oxygen saturation variability of intervals of $12 \mathrm{~s}$, has been validated for the prediction of OSA in adults [8] and in children with Down syndrome [9] but has not been studied in children without comorbidities. MCBRIDE et al. [10] evaluated 156 children without comorbidities, 78 were determined to have OSA based on clinical symptoms and 19 were not. The remaining 59 were undetermined. A delta $12 \mathrm{~s}$ index of $\geqslant 0.46$ was shown to predict OSA with a sensitivity of $97 \%$ and specificity of $79 \%$. They concluded that this can be used as a simple screening test to identify children with a high likelihood of OSA. A limitation of this study was that most of the patients did not have a confirmation of OSA with PSG.

The last abstract is about continuous positive airway pressure (CPAP) use for OSA in children. At present it is unclear what proportion of children can be successfully taken off CPAP and the factors that govern this cessation. KING et al. [11] described characteristics of a cohort of 18 children on CPAP for OSA, who were weaned off CPAP. These children had a median apnoea-hypopnoea index of 9.8 (5.7-46.0) events $\cdot h^{-1}$ at CPAP initiation, and after a median duration of $1.0(0.5-2.0)$ year, had an improvement in median apnoea-hypopnoea index to $3.0(1.9-4.8)$ events.h ${ }^{-1}$ at CPAP cessation. The reasons for CPAP cessation included improvement post airway surgery $(n=7)$, weight loss $(n=2)$ and improved symptoms and/or PSG parameters with time $(n=11)$. In four children, CPAP therapy was ceased after initial trial due to poor tolerance and low physician perceived clinical benefit. They concluded that children on CPAP should be regularly screened for ongoing symptoms and need for pressure support checked as a small group can be weaned.

In conclusion, there is a suggestion that OSA is a risk factor of early osteoporosis in children. Tracheal sounds and suprasternal pressure are promising sensors to detect respiratory events like apnoeas. Delta $12 \mathrm{~s}$, a measure of oxygen saturation, can be used as a simple screening test for OSA. 


\section{Paediatric asthma and allergy}

Several themes emerged from this year's sessions on paediatric asthma including risk factors for asthma development, asthma diagnosis, monitoring and management.

Maternal prenatal antibiotic use and absence of breastfeeding have been suggested as risk factors for asthma in children $[12,13]$. Two abstracts questioned these associations. Using data from Danish registers LiU et al. [14] performed a population based cohort study, which included 411883 children. Antibiotic use during pregnancy was found to be associated with childhood asthma in cohort analyses, but not in sibling analyses. The authors concluded that previously observed associations may be due to confounding factors. Similarly, a prospective cohort study of 377 unselected healthy children from birth to 6 years by Gorlanova et al. [15] found no association between breastfeeding with respiratory symptoms after adjustment for confounding factors. Importantly, the authors reported no differences in lung function or exhaled nitric oxide fraction ( $\left.F_{\mathrm{eNO}}\right)$ between breastfed versus non-breastfed children.

Asthma diagnosis is not straightforward, and there are no gold standard diagnostic criteria. DE JonG et al. [16] assessed the diagnostic accuracy of symptoms and clinical tests for childhood asthma in a cross-sectional study of 111 children. All underwent spirometry, $F_{\mathrm{eNO}}$, skin prick tests and challenge testing by exercise, methacholine and mannitol. A positive history of wheeze, $F_{\mathrm{eNO}}$ and challenge testing by exercise emerged as having the highest combined sensitivity and specificity for asthma diagnosis in children.

Several abstracts reported the role of $F_{\mathrm{eNO}}$ in asthma monitoring. Using individual participant data from seven studies, TURNER et al. [17] investigated the variability of $F_{\mathrm{eNO}}$ in children with stable asthma over a 3-month period. In 543 children with baseline $F_{\mathrm{eNO}}<50$ parts per billion, the median (interquartile range) absolute change and percentage change in $F_{\mathrm{eNO}}$ over 3 months were $+2 \mathrm{ppb}(-4-9)$ and $+10 \%(-25-66)$, respectively; whilst in 131 children with a baseline $F_{\mathrm{eNO}}$ of $\geqslant 50 \mathrm{ppb}$ the absolute and percentage change were $-8 \mathrm{ppb}(-28-18]$ and $-11 \%(-38-32)$, respectively.

DiAmant et al. [18] observed that $F_{\text {eNO }}$ positively correlated with severity for both day $(\mathrm{r}=0.263, \mathrm{p}=0.003)$ and night $(\mathrm{r}=0.211, \mathrm{p}=0.021)$ symptoms, albeit only weakly in 125 children with abnormal baseline $F_{\mathrm{eNO}}$ (>35 ppb). Lo et al. [19] conducted a cross-sectional study in 465 children with physician diagnosed or suspected asthma. Using global lung initiative reference equations to convert absolute spirometric values into z-scores they observed a significant but weak negative correlation between $F_{\text {eNO }}$ with both forced expiratory volume in $1 \mathrm{~s}\left(\mathrm{FEV}_{1}\right)(\mathrm{r}=-0.2046, \mathrm{p}<0.0001)$ and $\mathrm{FEV}_{1} /$ forced vital capacity $(\mathrm{FVC})(\mathrm{r}=-0.2042$, $\mathrm{p}<0.0001)$.

The recent Lancet Commission on asthma [20] highlighted the need for more personalised asthma treatment strategies. HeRnandez-PACHeCO et al. [21] performed a genome wide meta-analysis involving 2704 children to identify genes associated with inhaled corticosteroid response. 8.1 million genetic variants were meta-analysed. The authors reported 19 polymorphisms associated with asthma exacerbations despite inhaled corticosteroids (ICS) treatment. Interestingly, variants located at the CNTNAP5 gene were also found to be associated with changes in $\mathrm{FEV}_{1}$ following ICS treatment.

Mepolizumab and omalizumab have now been approved for the treatment of severe asthma in children from the age of 6 years across Europe. Eligibility criteria for paediatric patients are based on those for adults. DAvies et al. [22] investigated the eligibility criteria for either drug in a single paediatric asthma centre. Out of 67 children, 52\% were eligible for omalizumab, $80 \%$ for mepolizumab and $40 \%$ for both. The authors concluded that in contrast to adult cohorts, a large proportion of children with severe asthma met eligibility criteria for biologics, with significant overlap; and that paediatric-specific criteria are urgently needed.

MURPHY et al. [23] performed a systematic review and meta-analysis on the use of oral corticosteroids (OCS) in preschool children presenting to the emergency department with acute wheeze. Four studies were included and OCS use was not found to reduce the risk of hospitalisation (risk ratio 0.94, 95\% CI 0.8-1.12) or length of stay. The authors concluded that OCS should not be used in the emergency department for acute preschool wheeze.

In conclusion, an association between prenatal maternal antibiotic use and absence of breast feeding are not associated with asthma in children when confounding factors are excluded. History of wheeze, $F_{\mathrm{eNO}}$ and indirect challenge test reportedly had the best diagnostic utility for asthma diagnosis in children. $F_{\text {eNO }}$ only correlates weakly with both symptoms and $\mathrm{FEV}_{1}$. However, percentage change in $F_{\text {eNO }}$ may be more relevant than the absolute change. Paediatric specific criteria for biologic therapies are urgently needed. There is still poor evidence for the use of OCS in children with acute preschool wheeze. 


\section{Cystic fibrosis}

The changing landscape of cystic fibrosis (CF) and challenges to future care were discussed in detail during the Congress.

The Lancet Commission was set up to address the health and economic costs over the next three decades in order to identify how outcomes and care can be improved in this cohort of patient with the advent of disease modifying treatment and increased numbers of adult patients. The symposium arranged by the Commission further described four areas of collaboration [24]. First, Milan Macek spoke about the changing epidemiology of CF. Improved genetic understanding has led to diagnosis in non-European populations, not always presenting classically and a global initiative is currently looking at the penetrance of over 400 known causative genes. Furthermore, due to the uptake of new-born screening (NBS), preconception screening and improvements in care there is an ageing CF population with equal numbers in paediatric and adult services. Secondly, Susan Madge continued this theme in describing the challenges this will bring, with an emphasis on less invasive investigations becoming more important. She described the need for more specialist centres and an appreciation of the multisystem nature of the disease. The novel use of technology for self-monitoring and remote consultation also has a role to improve care. The future in terms of symptomology with new available treatments is unclear and so personalised management and problems of aging will be important.

Thirdly, Hector Gutierrez spoke about the challenges in building care in developing countries. Region-specific diagnostic screening protocols are important, but in some countries incidence is so low that NBS has not been adopted. Engaging countries and stakeholders would help to create networks, train medical staff and enhance access to treatment. Implementation of registries and collaboration between high performing centres and other centres is also seen as a way forward.

Finally, Marcus Mall completed the session by describing the changes in CF treatment over the years, to the current objective of individualised CF transmembrane conductance regulator modulation. Recent advances for patients with one or two F508 alleles using triple combination therapy were mentioned and the strong conceptual framework for development of further therapies for all. The costs of new medications and access to them are however a concern, pushing the need to know long-term clinical effectiveness and transparency in costing. These advances will enable the goal of changing the diagnosis of $\mathrm{CF}$ from a fatal to a treatable chronic disease.

The oral presentation session "Advances in care and monitoring of CF" reflected these issues. We heard in the Lancet Symposium how lumacaftor/ivacaftor reduced the rate of decline and exacerbations in people with $\mathrm{FEV}_{1}$ 40-90\% predicted. In this session, Tong et al. [25] presented clinical data on those with $\mathrm{FEV}_{1}<40 \%$, showing a reduced rate of exacerbations and a small increase in $\mathrm{FEV}_{1}$. However, this was complicated by a high discontinuation rate due to treatment side-effects. Complimentary to this, Mok et al. [26] showed quantitative computed tomography analysis (PRAGMA-CF) to be a sensitive measure of early structural changes in CF patients on modulator treatment. CотоN et al. [27] presented their meta-analysis of 61 pharmacological randomised controlled trials in patients with CF showing a small placebo response in body mass index (BMI) but not in $\mathrm{FEV}_{1}$ or CF Questionnaire Revised-Respiratory Domain questionnaires. Finally, OCANA et al. [28] presented work radically reducing the time to produce disease modelled personalised cells from pluripotent stem cells from months to 3-6 weeks; a key step in the development of personalised treatment.

Other papers in this session dealt with imaging, an area where we have seen huge advances in the last few years. STAHL et al. [29] described disease progression in children diagnosed clinically and via NBS, and showed the rate of exacerbations and absolute magnetic resonance imaging (MRI) scores to be lower in the NBS group, although their rate of progression of lung disease on MRI was not reduced. SMITH et al. [30] described advances in ventilation MRI, and demonstrated that combined xenon and proton structural MRI was highly sensitive to changes in lung ventilation heterogeneity before spirometry and Lung Clearance Index.

In conclusion, the evolving patient demographics, promising new and repurposed treatments along with modalities of tracking early CF lung disease will affect the way we treat these patients and their long-term health. The papers in this section explained these challenges and changes in more detail. These insights will provide further evidence and inroads into meeting the aims of the Lancet Commission and improve diagnosis and treatment of CF worldwide.

\section{Paediatric respiratory infection and immunology}

The presentations at 2019 European Respiratory Society Congress covered many aspects of paediatric respiratory infections. In particular, with regard to asthma and wheezing prevention strategies, the study 
by HaRveY et al. [31] demonstrated that in infants born to mothers with asthma, breastfeeding for at least 6 months was protective for wheeze, but not for bronchiolitis.

Two studies focused on protracted bacterial bronchitis (PBB). One by LAIRD et al. [32] investigated the prevalence of $\mathrm{PBB}$ in children from four remote communities of Western Australia. They found a chronic wet cough in 21 out of 191 children and a PBB prevalence of $10 \%$ (95\% CI 6-16\%). The other study by Grose-Hodge et al. [33] found that recurrence of PBB was significantly lower in children treated with a 6 weeks course of antibiotics compared to $\leqslant 4$ weeks course, suggesting a possible need to change the international guidelines for the PBB treatment.

Concerning "hospital in the home" intravenous antibiotic treatment of respiratory exacerbation in children with bronchiectasis, O'ROuRKe et al. [34] found no difference in the therapy duration, effectiveness and time to the next exacerbation when compared to hospital-based treatment.

As regards the genetic analysis of primary ciliary dyskinesia, in a Danish cohort of affected children, MARTHIN et al. [35] reported that mutations in CCDC40 were more frequent than mutations in DNAH5 and half of patients with these two mutations were diagnosed after 5 years of age and almost $10 \%$ of patients had normal nasal nitric oxide.

A hot topic of this session was the airway microbiota. De Koff et al. [36] found that in infants hospitalised for a lower respiratory tract infection, the occurrence of re-infection within 4-8 weeks was associated with younger age, antibiotic treatment, wheezing disease phenotype and an abundance of gram-negative bacteria in the nasopharyngeal microbiota. MAN et al. [37] compared the oral microbiota to the nasopharyngeal microbiota longitudinally in infants aged $<6$ months of age. They found that oral microbiota may induce changes in the nasopharyngeal microbiota prior to a respiratory infection especially in infants attending daycare. The abstract by CleRC et al. [38] suggested that there is a link between the oral, nasopharyngeal and intestinal microbiota and the presence of a stable microbiome network architecture is associated with respiratory health in infants up to 6 months of age.

Bronchiolitis and microbiota was one of the most discussed topic. The abstract by MulHolland et al. [39] demonstrated that, in infants hospitalised in paediatric intensive care units for bronchiolitis, the upper airway microbiota was similar to the lower airway microbiota. PERSIA et al. [40] demonstrated that in respiratory syncytial virus (RSV) bronchiolitis the nasopharyngeal microbiota have a reduced alfa-diversity compared to virus negative infants with bronchiolitis. The microbiota composition also differed between the genotype A and B of the RSV. This study showed that there is a strict correlation between microbiota composition and viral infection, however it still remains unclear if changes in the microbiota occur first or are caused by the virus.

Conejero et al. [41] reported the results of a trial with a sublingual polybacterial immunotherapy (MV130). 6 months of therapy reduced the number and duration of wheezing episodes children. In an in vitro model, the MV130 proved to be effective in training innate immune cells and in reducing viral infections.

In the field of RSV infection, XU et al. [42] reported new results of the MAKI trial. The use of palivizumab in preterm infants significantly lowered the DNA methylation in the nasal epithelium at the age of 6 years, suggesting that RSV infection in infancy has long-term effect on epigenetics.

Regarding bronchiolitis from RSV, PIERANGeli et al. [43] reported the phylogenetic analysis of the G gene of the RSV-A ON1. In RSV-A ON1 genotype several aminoacidic changes occurred over time in the hypervariable regions. In particular, during the 2017-2018 season, these aminoacidic changes appeared in sites never reported before and were associated with a worse clinical disease course.

NeNNA et al. [44] reported that in infants hospitalised for RSV bronchiolitis, viral factors (higher viral load, RSV genotype NA1) are associated with occurrence of recurrent wheezing after 3 years of follow-up in combination with host factors (exposure to smoking, family history of asthma and feeding with formula).

The Paediatric Respiratory Infection and Immunology section covered a lot of different topics. In particular it has been reported that breastfeeding is a protective factor for recurrent wheezing, while after RSV bronchiolitis the recurrence of wheezing is higher in infants that were infected with the RSV-ON1 genotype. Upper and lower respiratory microbiota are linked and their changes are associated with recurrence of respiratory infections and RSV bronchiolitis, while a stable network between the nasopharyngeal, the oral and the intestinal microbiota is associated with respiratory health in infants.

\section{Neonatology and paediatric intensive care}

Advances in neonatal pulmonology are rapidly developing as more infants are surviving being born prematurely. Novel techniques to assess long-term lung function alongside determining underlying disease 
mechanisms are promising research areas and thereby allow us to better understand and target respiratory complications of preterm birth.

HARRIs et al. [45] described a cluster analysis approach of the neonatal population. Innovative methods allow identification of multidimensional subgroups to further inform specific treatments. A cohort of 330 prematurely born infants was followed up to adolescence and a predictive algorithm was derived from decision tree analysis. Four main clusters were identified with superior lung function seen in those infants who received high frequency oscillation in the neonatal period. The other three clusters included infants born at a lower gestational age and with a higher incidence of bronchopulmonary pulmonary dysplasia. However, there was no difference in lung function concerning the two modes of respiratory support received.

LUNDBERG et al. [46] described the challenges faced by young children born prematurely, specifically in performing lung function tests at follow-up, with impulse oscillometry reported to be easier to perform [47]. The authors evaluated the feasibility of performance between the widely used dynamic spirometry and impulse oscillometry in 6-year-old children. Preterm infants experienced similar difficulties in spirometry as term infants, and there was strong coherence between the results of both techniques within the group of preterm infants. A pilot study by GuERra AzEvedo et al. [48] evaluated the application of a three-dimensional kinematic model for predicting tidal volumes. This novel method of $V_{\mathrm{T}}$ estimation by kinematic analysis was comparable to standard predicting measures of $V_{\mathrm{T}}$ per kilogram of body weight.

Prematurely born infants in early postnatal life exhibit a blunted hypoxic ventilatory response [49]. SIMPSON et al. [50] assessed preterm infants at 12-15 months of corrected postnatal age to establish whether the response was developed at this age. Interestingly, male infants $(p=0.009)$ and those with an increased duration of supplemental oxygen exposure $(\mathrm{p}=0.026)$ still had a diminished response. Prolonged supplemental oxygen exposure in the neonatal period renders preterm infants susceptible to adverse outcomes such as retinopathy of prematurity and bronchopulmonary dysplasia (BPD) [51]; however, the shared molecular pathways underlying these two entities remains unknown. WiCKRAMAsingHe et al. [52] utilised an animal model previously used to assess retinopathy of prematurity to study the development of chronic lung disease. Histopathology specimens of the lung and retina of neonatal mice exposed to hyperoxia were examined and compared to room-air controls. Their results showed alveolar wall thickening in combination with retinal vascular degeneration in the mice exposed to supplemental oxygen. This novel model gives us an insight into future developments of targeting a single therapy to ameliorate both pulmonary and retinal tissue damage.

Recent evidence has shown a reduction in the composite outcome of BPD or all-cause mortality in preterm infants treated with caffeine citrate [53]; however, the mechanism of action is complex and not fully understood. Two abstracts described the effect of caffeine therapy on pulmonary function in preterm infants. BARBERO et al. [54] performed rapid thoracoabdominal compression to assess lung function. Multivariate analysis showed that $\mathrm{FVC}$ and $\mathrm{FEV}_{0.5}$ were higher in the cohort of preterm infants receiving caffeine. Williams et al. [55] investigated the effect of caffeine on the electrical activity of the diaphragm in ventilated preterm infants. The authors found a significant increase in the amplitude of the electrical activity of the diaphragm, which peaked at 25 min post-caffeine administration $(\mathrm{p}=0.006)$ and was associated with an improvement in respiratory function. Prediction of extubation outcome remains a challenge in neonatal respiratory medicine with extubation failure rate at $33 \%$ [56]. Noninvasive monitoring of the electrical activity of the diaphragm can be used to assess neural respiratory drive [57]. Hunt et al. [58] aimed to determine the predictive ability of surface electromyography in extubation outcome. This method was tested in a cohort of 72 infants using the area under the receiver-operator characteristic curve to predict extubation success. However, it was shown that clinical variables remained better predictors of extubation success than diaphragmatic electrical activity $(\mathrm{AUC}=0.55)$ with weight at study being the best predictor (AUC=0.81).

Novel and promising methodologies were described, such as a shared histopathological animal model for BPD and retinopathy of prematurity, diaphragmatic surface electromyography and lung function following thoracoabdominal compression. Ex-preterm infants exhibit significant persisting pathology such as reduced hypoxic responses and poorer lung function in childhood. Prediction of extubation remains evasive as clinical variables are superior to surface diaphragmatic electromyography. A novel three-dimensional kinematic model was found to accurately predict tidal volumes and impulse oscillometry is a feasible modality of lung function measurement in ex-preterm infants at follow-up.

\section{Paediatric respiratory epidemiology}

The importance of early life environment and the development of respiratory diseases later in life is now one of the most important and frequently studied topics in respiratory research. Starting with intrauterine 
exposures, LunDHOLM et al. [59] found that: 1) the association between prenatal exposure to smoking and asthma in the offspring was strongest in the early years (5 and 18 months, moments when mother-infant activities or day care is usually started); 2) it was weaker when studying oral moist snuff with high nicotine content (therefore not due to nicotine); and 3) the effect was not present in the sibling comparison analysis (suggesting shared familial factors such as passive smoking). AbELLAN et al. [60] used data from 2685 mother-child pairs from eight European birth cohorts to show that bisphenol-A (BPA) exposure was detected in $79 \%$ of mothers during pregnancy, with a much lower exposure to other phenols, and that increasing prenatal BPA exposure tended to be associated with lower lung function $\left(\mathrm{FVC}\right.$ and $\left.\mathrm{FEV}_{1}\right)$ and increased odds of wheeze or asthma at 6 and 10 years of age. However, these results were not adjusted for breastfeeding, birthweight or postnatal phenol exposure.

The role of obesity on asthma development has not yet been well elucidated. Using cross-sectional data from the population-based Generation R cohort, Mensink-Bout et al. [61] found that both general fat and organ fat were associated with airway obstruction in lung function (increased FVC with decreased $\mathrm{FEV}_{1}$ / FVC), while only organ fat, independent of total fat mass, was associated with reported physician-diagnosed asthma. Peralta et al. [62] used data from the population-based INMA birth cohort study to show that, independent from departing birth size, children with accelerated BMI gain during the first years of life had lower $\mathrm{FEV}_{1} / \mathrm{FVC}$ ratio and higher $\mathrm{FVC}$ at school age, opposite to what occurred to those with lower birth size and slow BMI gain.

Long-term morbidity prediction and natural history of asthma are also research areas of interest. LONGO et al. [63] studied the long-term adverse outcomes of poor asthma control, and found that pre-schoolers with suboptimal asthma control in the 2 years following diagnosis from a Canadian birth cohort, had a higher risk of long-term poor control. In Sweden, Osvald et al. [64] reported that even though the rate of death from asthma is low in children and young adults (1-25 years), asthma increased the risk of all-cause mortality. The presence of life-limiting conditions modified this effect by increasing the risk.

Finally, an ecological study in the UK by WALKER et al. [65], showed that English regions with a higher number of annual hours of sunlight had lower annual lower respiratory tract infection admission rates. It is now necessary to assess if this association is explained by a possible vitamin D deficiency.

The influence of early life environment in lung health later in life is becoming clearer, as shown with the negative impact of prenatal tobacco smoke and BPA exposure. Accelerated BMI gain in infants may affect lung function at school age, while organ fat and not total fat mass was associated with a doctor's asthma diagnosis in children. Pre-schoolers with a suboptimal asthma control may have a poorer control in the long term, and asthma in children and young adults seems to increase all-cause mortality. In an ecological study, increased hours of sunshine was associated with reduced admissions for lower respiratory tract infections.

\section{Paediatric bronchology}

In the poster discussion session " a mixture of rare lung diseases", the discussion showed recent advances in primary ciliary dyskinesia (PCD), interstitial lung disease in children and respiratory and sleep physiology that ranged from diagnostic and therapeutic interventions to the search for follow-up interventions and predictors to optimised care and prognosis.

AMigo et al. [66] evaluated 51 patients with high clinical suspicion of PCD and concluded, that the combination of high-speed video-microscopy and immnunofluorescence can lead to the diagnosis in many cases. Another study of immnunofluorescence examination in 36 PCD suspected patients by ATAG et al. [67] revealed ciliary defects in $83 \%$ of patients. Authors emphasised the power of immnunofluorescence in the diagnosis of PCD. CHATZIPARASIDIs et al. [68] retrospectively analysed medical records of 235 patients referred to Athens PCD Centre with a suspicion of PCD on the basis of medical history. Unfortunately referral accuracy was low; $59.3 \%$ of referred patients scored $<5$ PICADAR points (cut-off score). EMIRALIOĞLU et al. [69] showed in a cohort of 46 Turkish patients with PCD that subjects with CCNO mutations are diagnosed earlier and those with CCDC40 or CCNO mutations had more severe lung disease and poorer nutritional status. CORULlón et al. [70] focused on psychological functioning of patients with PCD. $41.9 \%$ of the subjects presented with anxiety and $16.7 \%$ with depression with a tendency to underestimate the threat of the disease.

In a retrospective study, FERraro et al. [71] analysed airway to artery dimensions and the number of visible airways on chest computed tomography of 13 PCD patients. The authors showed that in PCD airways are more dilated compared to healthy controls.

Porcaro et al. [72] presented results of retrospective data analysis of 132 non-CF patients with diagnosis of bronchiectasis. Recurrent infections were the most common cause of bronchiectasis and chronic cough was the most common symptom at first evaluation. 
AINSWORTH et al. [73] characterised the airway microbiota by collecting nasal swabs and sputum samples of 28 children with bronchiectasis at the time of acute exacerbations and after treatment.

COST action 16125 "Enter-ChILD" WG6 assessed the registry-based capacity for identifying interstitial lung disease in children (chILD) and young adults across Europe. Authors identified several national, local and one international database. Many chILD conditions can be aggregated across identified databases and can help researchers to create cohorts for clinical trials [74]. CARLENs et al. [75] performed retrospective analysis and prospective follow-up of five cases with TBX4 mutation. Patients presented with different severity and progression of respiratory disease: three children required pulmonary hypertension treatment, three required oxygen supplementation, and one had lung transplantation at last follow-up. Ring et al. [76] performed a cross-sectional study of 31 chILD patients and aimed to utilise the hypoxic challenge test (HCT) as a surrogate assessment of inflight saturation. Desaturation $<90 \%$ occurred in $35 \%$ of patients during HCT without any relationship to lung function. HCT test should be considered in all children with diffuse lung disease despite normal lung function parameters and normal room air saturation.

MARCZAK et al. [77] prospectively assessed pulmonary function in 25 children aged $>4$ years diagnosed with persistent tachypnoea of infancy. In most patients with persistent tachypnoea of infancy, abnormalities in pulmonary function tests were observed. Air trapping and high airways resistance were common findings and ventilation heterogeneity was observed in the majority of them.

PARISI et al. [78] evaluated Lung Clearance Index results of 57 off-treatment childhood cancer survivors and 50 age-matched healthy controls and did not find any differences in lung function between groups. Grose-Hodge et al. [79] retrospectively investigated incidence of post-procedure complications of 155 paediatric flexible bronchoscopies with bronchoalveolar lavage. In this cohort, $8 \%$ of children experienced side-effects that led to discharge delay or re-admission to the hospital. Schramm et al. [80] conducted an international study and analysed 446 foreign body removals. Overall, severe complications occurred in $1 \%$ of all rigid procedures and in $0.8 \%$ of the flexible. ELDERs et al. [81] performed static and dynamic MRI studies of 48 patients who underwent open airway surgery for laryngotracheal stenosis. According to the authors, MRI is a suitable method for evaluation of structure and function of the upper airway in post laryngotracheal stenosis children.

In conclusion, immnunofluorescence can be crucial in the diagnosis of PCD. Particular mutation in PCD can predict severity of lung disease and nutritional status. Recurrent infections are the most common cause of bronchiectasis and chronic cough is the most common symptom at first evaluation. Hypoxic challenge test should be considered in all children with diffuse lung disease despite normal lung function parameters and normal room air saturation. In most patients with persistent tachypnoea of infancy, abnormalities in pulmonary function tests are observed.

\section{Lung and airway developmental biology}

The session comprised of seven oral presentations. Five presentations covered the field of basic lung research. Two presentations were clinical studies.

In their late breaking abstract, KuснівнотLA et al. [82] hypothesised that in the asthmatic airway, increased $\beta$-catenin signalling activates Notch resulting in increased differentiation of mucous cell in the airway epithelium. Using an in vitro model of asthmatic and healthy airway epithelium (primary bronchial epithelial cell) in an air-liquid interface culture, they did not observe significant changes in mRNA expression of $\beta$-catenin, Notch and their respective targets. This was confirmed by immunohistochemistry results. Furthermore, differentiation markers FOXJ1, FOXA2 and MUC5AC were not changed. Gain- and loss-of-function experiments of $\beta$-catenin and/or Notch signalling pathways in healthy primary bronchial epithelial cell are planned. The better understanding of mucous cell differentiation might open new therapeutic avenues.

In turn, ISAGO et al. [83] presented data implicating a role of transcriptional co-activator with PDZ-binding motif (TAZ) and Yes-associated protein (YAP) in controlling lung development at different stages by using conditional KO mice for TAZ and YAP. In addition, the results suggested the existence of a novel pathway between transforming growth factor- $\beta$ and Shh.

The research group of Alejandre Alcazar identified a novel KLF4-SMAD2-STAT3 axis being potentially responsible for lung regeneration in a mouse model of BPD. In detail, reduced ATII markers after hyperoxia were associated with reduced KLF4 expression and lung growth. This was confirmed by in vitro data using KLF4 gain-of-function and loss-of-function in MLE12 cells [84]. Another study from his group investigated the impact of maternal obesity on lung microvessels in the offspring. Indeed, maternal obesity led to increased levels of interleukin (IL)-6 and increased the risk of developing pulmonary arterial hypertension. They showed that IL-6-induced phosphorylation of STAT3, which sequestered FOXO1 in 
the cytoplasm. Using IL-6-/- mice they identified an IL-6-FOXO1 mediated hyperplasia of vascular smooth muscle cells which could be prevented by a FOXO1 activator (Paclitaxel) [85].

GIE et al. [86] aimed to characterise the effects of intermittent CPAP on lung function and structure in a preterm rabbit model of BPD. Lung function tests and analyses on alveolar, vascular and airway morphology revealed that hyperoxia significantly altered lung function and morphology. However, CPAP attenuated the functional and structural changes of hyperoxic lung injury.

A study by Hagman et al. [87] focused on the lung function of prematurely born infants (median 27 weeks of gestational age and birth weight $950 \mathrm{~g}$ ) at 12 years of age, compared with infants born at term. Using spirometry, impulse oscillometry, body plethysmography and diffusing capacity they showed that preterm birth is associated with an increased risk for obstructive airway disease and impaired lung function. This observation was independent of suffering from BPD or not.

The study of Hermelijn et al. [88] aimed to establish a clinical guide for systemic assessment of computed tomography imaging in congenital lung abnormalities. Based on an extensive literature search they suggested an uniform nomenclature and the use of objective radiologic features for the description of congenital lung abnormalities.

In conclusion, $\beta$-catenin signalling activates Notch resulting in increased differentiation of mucous cell in the airway epithelium. Transcriptional co-activator with PDZ-binding motif and Yes-associated protein are involved in controlling lung development at different stages. Novel KLF4-SMAD2-STAT3 axis might be responsible for lung regeneration in a mouse model of BPD. Maternal obesity leads to increased levels of IL-6 and increased risk of developing pulmonary arterial hypertension through IL-6-FOXO1 mediated hyperplasia of vascular smooth muscle cells. CPAP attenuates the functional and structural changes of hyperoxic lung injury in a BPD rabbit model. Preterm birth is associated with an increased risk for obstructive airway disease and impaired lung function, independent of suffering from BPD or not. Objective radiologic features are needed for systemic assessment of computed tomography imaging in congenital lung abnormalities.

Conflict of interest: R. Nenna has nothing to disclose. M. Slaats has nothing to disclose. R. Ersu has nothing to disclose. D. Lo has nothing to disclose. S. Saglani has nothing to disclose. C. Nissenbaum has nothing to disclose. A.R. Horsley reports grants from the NIHR, the Cystic Fibrosis Foundation and the Cystic Fibrosis Trust, and personal fees from Vertex Pharmaceuticals and Mylan, outside the submitted work. M. Proesmans has nothing to disclose. L. Petrarca has nothing to disclose. E. Williams has nothing to disclose. T. Dassios has nothing to disclose. C. Ardura-Garcia has nothing to disclose. L. Duijts reports a speaker fee for the 2019 International Congress and meeting fees for the Task Force on Bronchopulmonary Dysplasia (TF 2015-18) from the European Respiratory Society writing of the manuscript. H. Marczak has nothing to disclose. D. Snijders reports a grant for networking (no payment fee) from COST Action CA16125 outside the submitted work. R. Rottier has nothing to disclose. C-M. Chao has nothing to disclose. M.W Pijnenburg has nothing to disclose. J. Grigg reports honoraria for advisory boards from GSK, Vifor Pharmaceuticals, BV Pharma and AstraZeneca, and an honorarium for a talk from Novartis, outside the submitted work.

\section{References}

1 Chen YL, Weng SF, Shen YC, et al. Obstructive sleep apnea and risk of osteoporosis: a population-based cohort study in Taiwan. J Clin Endocrinol Metab 2014; 99: 2441-2447.

2 Knowles H. Hypoxic regulation of osteoclast differentiation and bone resorption activity. Hypoxia (Auckl) 2015; 3 73-82.

3 Sies NS, Nathan AM, Debruyne JA, et al. Association between childhood obstructive sleep apnoea and risk of early osteoporosis. Eur Respir J 2019; 54: Suppl. 63, PA910.

4 Omar A, Turan S, Bereket A. Reference data for bone speed of sound measurement by quantitative ultrasound in healthy children. Arch Osteoporos 2006; 1: 37-41.

5 Hizal MG, Polat SE, Ademhsn D, et al. Evaluation of sleep disorders in children with down syndrome. Eur Respir J 2019; 54: Suppl. 63, PA914.

6 Berry RB, Budhiraja R, Gottlieb DJ, et al. Rules for scoring respiratory events in sleep: update of the 2007 AASM Manual for the Scoring of Sleep and Associated Events. Deliberations of the Sleep Apnea Definitions Task Force of the American Academy of Sleep Medicine. J Clin Sleep Med 2012; 8: 597-619.

7 Amaddeo A, Sabil A, Olmo Arroyo J, et al. Evaluation of sleep apnoea in children using tracheal sounds and suprasternal pressure. ERJ Open Res 2019; 5: Suppl. 3, P133.

8 Magalang UJ, Dmochowski J, Veeramachaneni S, et al. Prediction of the apnea-hypopnea index from overnight pulse oximetry. Chest 2003; 124: 1694-1701.

9 Hill CM, Elphick HE, Farquhar M, et al. Home oximetry to screen for obstructive sleep apnoea in Down syndrome. Arch Dis Child 2018; 103: 962-967.

10 McBride A, See L, Shah M, et al. Delta 12s index as a screening tool for obstructive sleep apnoea in children. Eur Respir J 2019; 54: Suppl. 63, OA1593.

11 King Z, Josee-Leclerc M, Wales P, et al. Can CPAP therapy in pediatric OSA ever be stopped? J Clin Sleep Med 2019; 15: 1609-1612.

12 Dogaru CM, Nyffenegger D, Pescatore AM, et al. Breastfeeding and childhood asthma: systematic review and meta-analysis. Am J Epidemiol 2014; 179: 1153-1167. 
13 Loewen K, Monchka B, Mahmud SM, et al. Prenatal antibiotic exposure and childhood asthma: a population-based study. Eur Respir J 2018; 52: 1702070.

14 Liu X, Chen J. Maternal antibiotic use during pregnancy and asthma in children: population-based cohort study and sibling design. Eur Respir J 2019; 54: Suppl. 63, OA4942.

15 Gorlanova O, Appenzeller R, Fuchs O, et al. Impact of breastfeeding on lung function, respiratory and allergic diseases in school children. Eur Respir J 2019; 54: Suppl. 63, PA5425.

16 de Jong C, Pedersen E, Goutaki M, et al. Diagnosing asthma accurately in school-aged children suspected to have asthma. Eur Respir J 2019; 54: Suppl. 63, PA5433.

17 Turner S, Fielding S, Pijnenburg M, et al. By how much can exhaled nitric oxide vary over three months in children with stable asthma? Eur Respir J 2019; 54: Suppl. 63, PA5419.

18 Diamant N, Amirav I, Armoni-Domani K, et al. Fractional exhaled nitric oxide levels: an objective indicator for asthma severity. Eur Respir J 2019; 54: Suppl. 63, PA5420.

19 Lo D, Danvers L, Roland D, et al. Raised FeNO is associated with lower FEV1 and FEV1/FVC in children with asthma. Eur Respir J 2019; 54: Suppl. 63, PA5423.

20 Pavord ID, Beasley R, Agusti A, et al. After asthma: redefining airways diseases. Lancet 2018; 391: 350-400.

21 Hernandez-Pacheco N, Vijverberg SJ, Gorenjak M, et al. Meta-analysis of inhaled corticosteroids response in children with asthma. Eur Respir J 2019; 54: Suppl. 63, PA5434.

22 Davies B, Chinthala D, Frost S, et al. Mepolizumab eligibility in children with severe asthma - do we need paediatric specific criteria? Eur Respir J 2019; 54: Suppl. 63, PA950.

23 Murphy J, King C, Kapitein B, et al. Oral steroids for preschool children with acute wheeze: a systematic review and meta-analysis. Eur Respir J 2019; 54: Suppl. 63, OA4941.

24 Bell SC, Mall MA, Gutierrez H, et al. The future of cystic fibrosis care: a global perspective. Lancet Respir Med 2020; 8: 65-124.

25 Tong K, Dorahy D, France M, et al. A multicentre, observational cohort study to determine the efficacy and safety of lumacaftor/ivacaftor in patients with severe lung disease and cystic fibrosis. Eur Respir J 2019; 54: Suppl. 63, OA2599.

26 Mok LC, Juárez AG, Kenmer-Van De Corput M, et al. The effect of CFTR modulators on CT outcome in cystic fibrorsis. Eur Respir J 2019; 54: Suppl. 63, OA2645.

27 Coton J, Le $\mathrm{HH}$, Janiaud $\mathrm{P}$, et al. Do patients with cystic fibrosis participating in clinical trials demonstrate placebo response? A meta-analysis. Eur Respir J 2019; 54: Suppl. 63, OA2824.

28 Ocana SC, Wong A, Aushev M, et al. How can gene-editing of human pluripotent stem cells help cystic fibrosis? Eur Respir J 2019; 54: Suppl. 63, OA1145.

29 Stahl M, Steinke E, Seitz C, et al. Progression of lung disease detected by MRI and impact of NBS in preschoo children with cystic fibrosis. Eur Respir J 2019; 54: Suppl. 63, OA2001.

30 Smith L, Hughes D, Chan H, et al. $1 \mathrm{H}$ and 129 Xe MRI to detect functional and structural lung disease in sub-clinical cystic fibrosis. Eur Respir J 2019; 54: Suppl. 63, OA4334.

31 Harvey SM, Murphy VE, Gibson PG, et al. The association between breastfeeding and respiratory health in infants born to women with asthma: a secondary analysis of two cohort studies. Eur Respir J 2019; 54: Suppl. 63, PA5003.

32 Laird P, Walker R, Chang A, et al. Prevalence of chronic wet cough and protracted bacterial bronchitis in Aborigenal children. Eur Respir J 2019; 54: Suppl. 63, PA4991.

33 Grose-Hodge E, Carroll W, Rainford N, et al. Duration of initial antibiotic course is associated with recurrent relapse in protracted bacterial bronchitis. Eur Respir J 2019; 54: Suppl. 63, PA5002.

34 O’Rourke C, Schilling S, Martin R, et al. A comparison of in-hospital and HITH-based treatment of respiratory exacerbations in children with bronchiectasis. Eur Respir J 2019; 54: Suppl. 63, PA5001.

35 Marthin JK, Philipsen MC, Duno M, et al. Genetic profile, nasal nitric oxide and age at diagnosis in 60 Danish PCD patients. Eur Respir J 2019; 54: Suppl. 63, PA5004.

36 De Koff EM, Man WH, van Houten MA, et al. Resilience of the nasopharyngeal microbiota following childhood lower respiratory tract infection. Eur Respir J 2019; 54: Suppl. 63, PA4993.

37 Man WH, Clerc M, De Steenhuijsen Piters W, et al. Loss of microbial topography between oral and nasopharyngeal microbiota and development of respiratory infection early in life. Eur Respir J 2019; 54: Suppl. 63, PA4995.

38 Clerc M, Reyman M, Man WH, et al. Maturation on microbial networks across body sites is associated with susceptibility to childhood respiratory infection. Eur Respir J 2019; 54: Suppl. 63, PA4996.

39 Mulholland A, Broderick D, Missen S, et al. The lower airway microbiota in infants with severe bronchiolitis is largely similar to the upper airway microbiota. Eur Respir J 2019; 54: Suppl. 63, PA4992.

40 Persia S, Frassanito A, Nenna R, et al. Nasal microbiota in RSV microbiota. Eur Respir J 2019; 54: Suppl. 63, PA4994.

41 Hall LC, Garcia AN, Brandi P, et al. Bacterial immunotherapy in children with wheezing attacks: clinical impact and mechanism of action. Eur Respir J 2019; 54: Suppl. 63, PA4998.

$42 \mathrm{Xu} \mathrm{C}$, Scheltema NM, Qi C, et al. Infant RSV infection changes nasal epithelial DNA methylation at 6 years of age. Eur Respir J 2019; 54: Suppl. 63, PA4999.

43 Pierangeli A, Scagnolari C, Viscido A, et al. Variability in the glycoprotein G gene of RSV-A ON1 strains causing bronchiolitis. Eur Respir J 2019; 54: Suppl. 63, PA4997.

44 Nenna R, Frassanito A, Petrarca L, et al. Bronchiolitis from RSV (NA1, ON1 and BA) and recurrent wheezing over 3 years follow-up. Eur Respir J 2019; 54: Suppl. 63, PA5000.

45 Harris C, Lunt A, Peacock J, et al. Predicting long term lung function outcomes of prematurely born infants using cluster analysis. Eur Respir J 2019: 54: Suppl. 63, OA273.

46 Lundberg B, Melén E, Thunqvist P, et al. Correlation between impulse oscillometry and spirometry outcomes in a cohort of extremely preterm 6-year olds and controls. Eur Respir J 2019; 54: Suppl. 63, OA276.

47 Komarow HD, Myles IA, Uzzaman A, et al. Impulse oscillometry in the evaluation of diseases of the airways in children. Ann Allergy Asthma Immunol 2011; 106: 191-199.

48 Azevedo IG, Figueiredo AG, Lopes L, et al. Application of a three-dimensional kinematic model for prediction of tidal volume in newborns: a pilot study. Eur Respir J 2019; 54: Suppl. 63, OA279.

49 Nock ML, Difiore JM, Arko MK, et al. Relationship of the ventilatory response to hypoxia with neonatal apnea in preterm infants. J Pediatr 2004; 144: 291-295. 

in babies born preterm. Eur Respir I 2019; 54: Suppl. 63, OA277.

of Med 2010; 15: 230-235.

52 Wickramasinghe L, Tsantikos E, Lau M, et al. Lung and eye pathology develop concurrently in neonatal supplemental oxygen model. Eur Respir J 2019; 54: Suppl. 63, OA274.

53 Shenk EE, Bondi DS, Pellerite MM, et al. Evaluation of timing and dosing of caffeine citrate in preterm neonates for the prevention of bronchopulmonary dysplasia. J Pediatr Pharmacol Ther 2018; 23: 139-145.

54 Barbero PGM, Mondéjar-López P, Garcia-Marcos L, et al. Effects of caffeine therapy on preterm infant's lung function. Eur Respir J 2019; 54: Suppl. 63, OA280.

55 Williams E, Jeyakara J, Hunt $\mathrm{K}$, et al. Influence of caffeine on the electrical activity of the diaphragm of mechanically ventilated, very premature infants. Eur Respir J 2019; 54: Suppl. 63, OA278.

56 Kavvadia V, Greenough A, Dimitriou G. Prediction of extubation failure in preterm neonates. Eur J Pediatr 2000, 159: $227-231$.

57 Jeffreys E, Hunt KA, Dassios T, et al. Diaphragm electromyography results at different high flow nasal cannula flow rates. Eur J Pediatr 2019; 178: 1237-1242.

58 Hunt K, Hunt I, Dassios T, et al. Prediction of infant extubation using surface diaphragm electromyography. Eur Respir J 2019; 54: Suppl. 63, OA275.

59 Lundholm C, Gunnerbeck A, Brian D, et al. Tobacco exposure in utero and childhood asthma and wheeze - a register-based cohort study. Eur Respir J 2019; 54: Suppl. 63, OA4968.

60 Abellan A, Mensink-Bout R, Chatzi L, et al. Prenatal exposure to phenols and lung function, wheeze, and asthma in school-age children from 8 European birth cohorts. Eur Respir J 2019; 54: Suppl. 63, OA4969.

61 Mensink-Bout R, Van Meel ER, Santos S, et al. General and organ fat measures and the risk of lower lung function and asthma in childhood. Eur Respir J 2019; 54: Suppl. 63, OA4967.

62 Peralta GP, Montazeri P, Abellan A, et al. Early infancy BMI trajectories and lung function and asthma during childhood. Eur Respir J 2019; 54: Suppl. 63, OA4966.

63 Longo C, Blais L, Brownell M, et al. Asthma control in preschoolers: a strong predictor of long-term morbidity. Eur Respir J 2019; 54: Suppl. 63, OA4971.

64 Osvald EC, Bower H, Lundholm C, et al. Asthma and all-cause mortality in children and young adults - a Swedish population based study. Eur Respir J 2019; 54: Suppl. 63, OA4972.

65 Walker J, Gilchrist F, Carroll W. Less sun, more cough: annual hours of sunshine are inversely associated with hospital admissions for children with lower respiratory tract infection. Eur Respir J 2019; 54: Suppl. 63, OA4970.

66 Amigo SR, Redon NB, Tarruella NC, et al. Preliminary results of high-speed video-microscopy and immunofluorescence analysis in a Spanish cohort of patients with primary ciliary dyskinesia. Eur Respir J 2019; 54: Suppl. 63, OA385.

67 Atag E, Hjeij R, Ikizoglu NB, et al. Immunofluorescense staining results in respiratory epithelial cells of patients with suspected PCD from Marmara University. Eur Respir J 2019; 54: Suppl. 63, OA386.

68 Chatziparasidis G, Mpoutopoulou B, Angeliki G, et al. PICADAR score as an evaluation tool of Greek physicians' PCD awareness. Eur Respir J 2019; 54: Suppl. 63, OA387.

69 Emiralioğlu N, Taskiran E, Kosukcu C, et al. The correlation between clinical characteristics and molecular genetic analysis results of primary ciliary dyskinesia patients: Hacettepe University Experience. Eur Respir J 2019; 54: Suppl. 63, OA382.

70 Corullón SC, Valero-Moreno S, Escribano-Montaner A, et al. Adaptation to disease and anxiety-depressive clinic in the paediatric patient with primary ciliary dyskinesia. Eur Respir J 2019; 54: Suppl. 63, OA384.

71 Ferraro VA, Andrinopoulou ER, Tiddens HA, et al. Airway-artery quantitative assessment in children with primary ciliary dyskinesia using chest computed tomography. Eur Respir J 2019; 54: Suppl. 63, OA383.

72 Porcaro F, Ullmann N, Cutrera R. Non-cystic fibrosis bronchiectasis in children: a single center experience. Eur Respir J 2019; 54: Suppl. 63, OA388.

73 Ainsworth A, Regtien T, Broderick D, et al. The effect of exacerbations on the airway microbiota in children with non-CF bronchiectasis. Eur Respir J 2019; 54: Suppl. 63, OA389.

74. Carlens J, Ullmann N, Kerem E, et al. A survey of children's interstitial lung disease (ChILD) databases across the EU and an ability to identify pan-registry clinical trial cohorts. Eur Respir J 2019; 54: Suppl. 63, OA392.

75 Carlens J, Schwerk N, Länger F, et al. Diffuse lung disease and pulmonary hypertension related to TBX4 mutation in 5 children. Eur Respir J 2019; 54: Suppl. 63, OA390.

76 Ring A, Sisman Y, Buchvald F, et al. Hypoxic challenge test in patients previous treated for chILD conditions. Eur Respir J 2019; 54: Suppl. 63, OA391.

77 Marczak H, Peradzynska J, Lange J, et al. Pulmonary function in children with persistent tachypnoea of infancy. Eur Respir J 2019; 54: Suppl. 63, OA276.

78 Parisi GF, Cannata E, Papale M, et al. Lung clearance index for evaluation of late complications of cancer therapy in children. Eur Respir J 2019; 54: Suppl. 63, OA399.

79 Grose-Hodge E, Carroll W, Alexander J, et al. Incidence of post-procedure complications in children undergoing elective flexible bronchoscopy. Eur Respir J 2019; 54: Suppl. 63, OA395.

80 Schramm D, Vossen C, Snijders D, et al. Foreign body removal in childhood - international study about preference, performance and complications. Eur Respir J 2019; 54: Suppl. 63, OA396.

81 Elders B, Ciet P, Wielopolski P, et al. The larynx after open airway surgery for laryngotracheal stenosis: a MRI study in children. Eur Respir J 2019; 54: Suppl. 63, OA398.

82 Kuchibhotla VNS, Read J, Heijink IH, et al. Role of $\beta$-catenin and Notch signalling in increased airway mucous cell differentiation in asthma. Eur Respir J 2019; 54: Suppl. 63, OA3602.

83 Isago H, Mitani A, Kohno S, et al. The Hippo pathway effectors TAZ and YAP are sequentially required in lung development. Eur Respir J 2019; 54: Suppl. 63, OA761.

84 Mohr J, Koch M, Danopoulos S, et al. Krüppel-like Factor 4 is a Stat3-Smad2 regulator in ATII cells determining ATII cell fate during lung development and hyperoxia-induced lung injury. Eur Respir J 2019; 54: Suppl. 63, OA2277. 
85 Jentgen V, Dinger K, Vohlen C, et al. FoxO1 activation protects against IL-6-mediated perinatal metabolic programming of lung micro-vessels. Eur Respir J 2019; 54: Suppl. 63, OA2281.

86 Gie A, Salaets T, Deprest J, et al. The influence of intermittent CPAP on hyperoxic lung injury in a preterm rabbit model of bronchopulmonary dysplasia. Eur Respir J 2019; 54: Suppl. 63, OA392.

87 Hagman C, Björklund L, Bjermer L, et al. Development of lung function in children born preterm with and without bronchopulmonary dysplasia - a follow-up study at 12 years of age. Eur Respir J 2019; 54: Suppl. 63, OA1657.

88 Hermelijn S, Elders B, Ciet P, et al. A clinical guide in the structured assessment of CT-imaging in congenital lung abnormalities. Eur Respir J 2019; 54: Suppl. 63, OA3574. 